\title{
Topical vs Peribulbar Anesthesia: Comparison of Anterior Chamber Depth and the Resultant Visual Outcome After Phacoemulsification
}

This article was published in the following Dove Press journal: Clinical Ophthalmology

\author{
Mayuresh P Naik' \\ Harinder Singh Sethi ${ }^{2}$ \\ Amita Yadav ${ }^{2}$ \\ 'Department of Ophthalmology, H.I.M.S.R \\ \& H.A.H. Centenary Hospital, Alaknanda, \\ New Delhi I 10062, India; ${ }^{2}$ Department of \\ Ophthalmology, V.M.M.C \& Safdarjung \\ Hospital, Ansari Nagar, New Delhi I I0029, \\ India
}

Purpose: To compare anterior chamber depth and postoperative visual outcome in patients undergoing phacoemulsification under topical vs peribulbar anesthesia.

Materials and Methods: Prospective, randomized, comparative observational study.

Sample size: 110 eyes with 55 eyes each.

- Group I: Patients undergoing phacoemulsification under topical anesthesia.

- Group II: Patients undergoing phacoemulsification under peribulbar anesthesia.

Once patients were selected, baseline a standard ophthalmic examination was done including best-corrected visual acuity (BCVA), refraction, IOP by NCT, anterior segment evaluation with slit lamp biomicroscopy, keratometry, axial length, and ACD measurement by IOL master. Postoperatively, the patients were reviewed at day 1, week 1, week 6 for the same parameters.

Statistics:

(1) Quantitative variables: Paired and unpaired $t$-test.

(2) Qualitative variables: Chi square test.

A $P$-value of $<0.05$ was considered statistically significant.

Results: Inter-group comparisons of post-operative change in ACD at 1-week post-op $(P$-value $<0.001)$ and 6-week post-op $(P$-value $<0.001)$ were statistically significant when compared to the pre-op values. The mean spherical equivalent in group I was $0.27 \pm 0.26 \mathrm{~d}$ and that in group II was $1 \pm 0.32 \mathrm{~d}$ at 1 -week post-op. The mean spherical equivalent in group I was $0.23 \pm 0.20 \mathrm{~d}$, while that in group II was $0.85 \pm 0.64 \mathrm{~d}$ at 6 -week post-op. This difference was statistically significant both at 1 -week post-op $(P$-value $=0.002)$ and 6 -week post-op $(P$-value $<0.001)$.

Conclusion: Post-phacoemulsification, the ACD is more after peribulbar anesthesia as compared to topical anesthesia. Post-op refractive outcome is better with the use of topical anesthesia.

Keywords: phacoemulsification, topical anesthesia, peribulbar anesthesia, ACD, MSE

\section{Introduction}

Phacoemulsification was first introduced by Charles Kelman in 1967. IOL implantation is done according to the power of lens calculated using various IOL calculation formulae. By customizing the IOL during cataract surgery, we can provide patients with best refractive outcomes, even high myopes and hypermetropes. Most of the modern IOL power calculation formulae are based upon the theoretical
Correspondence: Mayuresh P Naik

Department of Ophthalmology, H.

\& H.A.H. Centenary Hospital, Room No.

3 of Eye OPD, Ist Floor of OPD Building

Near GK-2, Alaknanda, New Delhi

I 10062, India

Tel +9I-8287344576

Email mayureshpnaik@gmail.com 


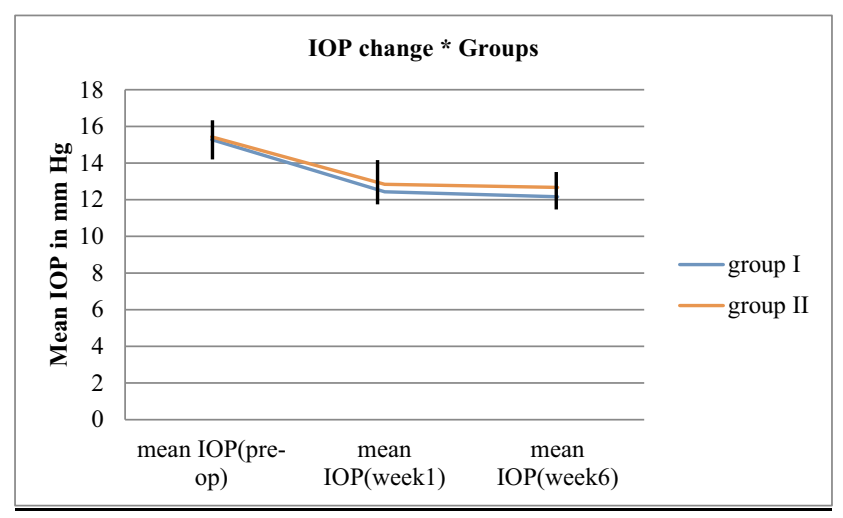

Figure I Line diagram depicting comparison of IOP in both the groups.

equation given by Fyoderov and its modifications. The only variable which cannot be determined preoperatively is effective lens position (ELP), so the modern formulae try to calculate it more accurately. ${ }^{1-3}$

Phacoemulsification affects anterior chamber depth (ACD) due to mechanical and patient factors. Example mechanical factors are phacoemulsification machine parameters, IOL thickness, IOL design, etc. Patient factors include grade of cataract, wound closure adequacy, zonular strength, anxiety, eye movements, etc. The type of anesthesia may be a contributing factor for determining ACD. The ACD determines the final resting position of IOL (ELP, as described above) and, thus, the resultant final refractive status of the eye. This study was undertaken to evaluate the probable effect of topical and peribulbar anesthesia on ACD and in turn on the refractive outcomes of the surgery.

\section{Materials and Methods}

Written and informed consent was taken from all patients. This study was approved by the Institutional Ethics Committee (EIC - IRB). All procedures performed in studies involving human participants were in accordance with the 1964 Helsinki declaration and its later amendments.

This study was a prospective observational comparative study conducted on patients visiting OPD at Tertiary eye hospital (VMMC \& Safdarjung Hospital, New Delhi, Department of Ophthalmology) having 110 eyes, randomized into two groups with 55 eyes each.

- Group I: Patients underwent phacoemulsification under Topical anesthesia.

- Group II: Patients underwent phacoemulsification under Peribulbar anesthesia.
The randomization was done using randomization software (table of random numbers) and the study was single blind, ie, the observer assessing the patients post-operatively was blind to the type of anesthesia used during surgery.

\section{Inclusion Criteria}

- Age $>40$ years.

- Immature senile cataract of grade I, II, III (LOCS-III classification).

\section{Exclusion Criteria}

- Patients with associated glaucoma.

- History of trauma.

- History of steroid induced cataract.

- Intraoperative complications affecting ACD (Posterior capsular rupture or zonular dialysis).

- Axial length $<22 \mathrm{~mm}$ or $>24 \mathrm{~mm}$.

- Any other ocular condition which effects ACD like healed uveitis, dislocated lens, etc.

- Systemic diseases like diabetes.

- Allergy to lignocaine, bupivacaine, proparacaine.,

\section{Procedure and Data Collection}

On visit 0 (on first visit to OPD), a preliminary screening assessment and examination was done on patients selected on the basis of inclusion and exclusion criteria.

Once patients were selected, baseline standard ophthalmic examination was done including Best-corrected visual acuity (BCVA), Refraction, Intraocular pressure (IOP) by Non-contact tonometry (NCT), Anterior segment evaluation with slit lamp biomicroscopy, Keratometry, axial length, and ACD measurement by IOL MASTER, Fundus examination by direct and indirect ophthalmoscopy.

Group I underwent uneventful phacoemulsification under topical anesthesia with two drops of $0.5 \%$ Proparacaine repeated twice, each instillation 5 minutes apart. Group II underwent uncomplicated phacoemulsification under peribulbar anesthesia comprising of $3 \mathrm{~mL}$ of preservative-free $2 \%$ Lignocaine and $3 \mathrm{~mL}$ of $0.5 \%$ Bupivacaine injected into the peribulbar space followed by gentle massage. ${ }^{4,5}$ All patients were operated on by the same surgeon using the same phaco machine (Infiniti ${ }^{\circledR}$ Vision System Ozil ${ }^{\circledR}$ phacoemulsification platform ${ }^{\odot}$ Alcon, Fort Worth, TX) under similar settings and received the same IOL (Superflex $620 \mathrm{H}$ single-piece foldable hydrophilic acrylic IOL with $6.25 \mathrm{~mm}$ optic, $12.50 \mathrm{~mm}$ overall length ${ }^{\circ}$ Rayner Intraocular Lenses Ltd.). 
Post-operatively, the patients were reviewed at day 1 (Visit 1), week 1 (Visit 2), and week 6 (Visit 3), and evaluated for Refraction, Visual acuity by Snellen chart, Anterior segment evaluation by slit lamp, and ACD by IOL MASTER. These parameters were assessed in all patients enrolled in both groups and a comparison was done to assess any statistical significance. Quantitative variables were compared using the paired and unpaired t-tests and a $P$-value $<0.05$ was considered significant (power of study $90 \%$ ).

\section{Results}

\section{Age and Sex Distribution}

The mean age in group I was $59.2 \pm 9.8$ years (range $=44-87$ years), whereas that in group II was $59.5 \pm 11.1$ years (range $=41-80$ years). The age distribution was comparable in both the groups $(P$-value $=0.71)$.

Group I had 34 males and 21 females. Group II had 28 males and 27 females.

The sex distribution was comparable in both groups $(P$-value $=0.82)$.

\section{Visual Acuity}

The mean spherical equivalent in group I was $0.27 \pm 0.26$ $\mathrm{D}$ and that in group II was $1 \pm 0.32 \mathrm{D}$ at 1 -week postop (Table 1). This difference in spherical equivalent in both the groups was statistically significant $(P$-value $=0.002)$.

The mean spherical equivalent of group I was 0.23 $\pm 0.20 \mathrm{D}$, while the mean spherical equivalent of group II was $0.85 \pm 0.64 \mathrm{D}$ 6-weeks post-op, which resulted in a statistically significant difference between the two groups $(P$-value $<0.001)$ (Table 2$)$.

\section{Intraocular Pressure (IOP)}

Pre-operatively, the mean IOP of group I was $15.28 \pm 1.65$ $\mathrm{mmHg}$ and that of group II was $15.43 \pm 1.17 \mathrm{mmHg}$, which was comparable in both the groups $(P$-value $=0.54)$.

Post-operatively, in Group I, mean IOP at pre-op, 1-week post-op, 6-week post-op was $15.28 \pm 1.65 \mathrm{mmHg}$, $12.43 \pm 1.89 \mathrm{mmHg}, 12.16 \pm 1.10 \mathrm{mmHg}$, and this intragroup decrease was statistically significant both at 1 -week $(P$-value $=0.04)$ and 6 weeks $(P$-value $=0.02)$.

Similarly in Group II, mean IOP at pre-op, 1 week post-op, and 6-week post-op was $15.43 \pm 1.17 \mathrm{~mm} \mathrm{Hg}$, $12.84 \pm 1.00 \mathrm{~mm} \mathrm{Hg}$, and $12.67 \pm 0.99 \mathrm{~mm} \mathrm{Hg}$, and this intra-group decrease was statistically significant both at 1 week $(P$-value $=0.04)$ and 6 weeks $(P$-value $=0.03)$.

Inter-group comparisons of post-operative IOP between Group I and Group II were not statistically significant for 1 -week post-op $(P$-value $=0.39)$ and 6 -week post-op $(P$-value $=0.36)$ (Figure 1).

\section{ACD}

Pre-operatively, mean pre-op ACD of Group I was 3.15 $\pm 0.39 \mathrm{~mm}$ and that of Group II was $3.05 \pm 0.48 \mathrm{~mm}$, which was comparable between the groups $(P$-value $=0.612)$.

Post-operatively, the intra-group change in ACD was statistically significant both at 1 -week post-op $(P$-value $<0.0001)$ as well as 6 -week post-op ( $P$-value $<0.0001)$ when compared to their pre-op values, depicting a progressive increase in central ACD in Group I and II both (Tables 3 and 4).

Inter-group comparisons of post-operative change in $\mathrm{ACD}$ at 1 -week post-op $(P$-value $<0.001)$ and 6 -week post-op

Table I Distribution of Patients with Respect to Post-Op Visual Acuity in Groups I and II at I Week

\begin{tabular}{|l|l|l|l|l|}
\hline \multirow{2}{*}{ VA } & \multicolumn{2}{|l|}{ Unaided } & \multicolumn{2}{l|}{ Best Corrected } \\
\cline { 2 - 5 } & Group I & Group II & Group I & Group II \\
\hline $6 / 6$ or $6 / 6 \mathrm{p}$ & $19 / 55(34.54 \%)$ & $10 / 55(18.18 \%)$ & $32 / 55(58.18 \%)$ & $18 / 55(32.72 \%)$ \\
$6 / 9$ or $6 / 9 \mathrm{p}$ & $30 / 55(54.14 \%)$ & $28 / 55(50.91 \%)$ & $20 / 55(36.36 \%)$ & $29 / 55(52.72 \%)$ \\
$\leq 6 / 12$ & $6 / 55(10.91 \%)$ & $17 / 55(30.91 \%)$ & $3 / 55(5.45 \%)$ & $8 / 55(14.54 \%)$ \\
\hline
\end{tabular}

Table 2 Distribution of Patients with Respect to Post-Op Visual Acuity in Groups I and II at 6 Weeks

\begin{tabular}{|l|l|l|l|l|}
\hline \multirow{2}{*}{ VA } & \multicolumn{2}{|l|}{ Unaided } & \multicolumn{2}{l|}{ Best Corrected } \\
\cline { 2 - 5 } & Group I & Group II & Group I & Group II \\
\hline $6 / 6$ or $6 / 6 \mathrm{p}$ & $20 / 55(36.36 \%)$ & $10 / 55(18.18 \%)$ & $35 / 55(63.6 \%)$ & $22 / 55(40 \%)$ \\
$6 / 9$ or $6 / 9 \mathrm{p}$ & $32 / 55(58.18 \%)$ & $30 / 55(54.54 \%)$ & $18 / 55(32.7 \%)$ & $27 / 55(49 \%)$ \\
$\leq 6 / 12$ & $3 / 55(5.4 \%)$ & $15 / 55(27.27 \%)$ & $2 / 55(3.6 \%)$ & $6 / 55(10 \%)$ \\
\hline
\end{tabular}


Table 3 ACD at Pre-Op, I Week Post-Op, and 6 Weeks PostOp for Group I (Intra-Group Comparison)

\begin{tabular}{|c|c|c|c|c|c|c|}
\hline & & $\begin{array}{l}\text { Mean } \\
(\mathrm{mm})\end{array}$ & $\mathbf{N}$ & SD & SE Mean & $P$-value \\
\hline PAIR I & $\begin{array}{l}\text { Pre-op } \\
\text { ACD } \\
\text { I week }\end{array}$ & $\begin{array}{l}3.1545 \\
3.7375\end{array}$ & $\begin{array}{l}55 \\
55\end{array}$ & $\begin{array}{l}0.39722 \\
0.43249\end{array}$ & $\begin{array}{l}0.05308 \\
0.05779\end{array}$ & $<0.0001$ \\
\hline PAIR 2 & $\begin{array}{l}\text { Pre-op } \\
\text { ACD } \\
6 \text { weeks }\end{array}$ & $\begin{array}{l}3.1545 \\
3.9120\end{array}$ & $\begin{array}{l}55 \\
55\end{array}$ & $\begin{array}{l}0.39722 \\
0.45485\end{array}$ & $\begin{array}{l}0.05308 \\
0.06078\end{array}$ & $<0.0001$ \\
\hline
\end{tabular}

Table 4 ACD at Pre-Op, I Week Post-Op, and 6 Weeks PostOp for Group II (Intra-Group Comparison)

\begin{tabular}{|l|l|l|l|l|l|l|}
\hline & & $\begin{array}{l}\text { Mean } \\
(\mathbf{m m})\end{array}$ & $\mathbf{N}$ & SD & SE Mean & P-value \\
\hline PAIR I & $\begin{array}{l}\text { Pre-op } \\
\text { ACD } \\
\text { I week }\end{array}$ & 3.0480 & 55 & 0.47917 & 0.06403 & $<0.0001$ \\
\hline PAIR 2 & $\begin{array}{l}\text { Pre-op } \\
\text { ACD } \\
6 \text { weeks }\end{array}$ & 3.0480 & 55 & 0.56195 & 0.07509 & 0.47917 \\
\hline .2282 & 55 & 0.064066 & 0.07225 & $<0.0001$ \\
\hline
\end{tabular}

$(P$-value $<0.001)$ were also statistically significant when compared to the pre-op values (Table 5).

\section{Lens Thickness}

Lens thickness was calculated pre-operatively and was not significantly different in the two groups $(P$-value $=0.95)$.

No anesthesia-related complications were documented in either group.

No patient required additional anesthesia during the surgery in either group.

None of the patients experienced any pain or discomfort during the surgery.

\section{Discussion}

Topical anesthesia was first used by Koller in the form of cocaine. It was first used by Kershner ${ }^{1}$ for phacoemulsification in an attempt to reduce the needle related complications of local anesthesia. Topical anesthesia has significant advantages including ease of application, faster onset of action, minimal discomfort, faster recovery, as well as none of the life or sight threatening complications as with peribulbar and retrobulbar anesthesia. It not only allows full and free ocular movements, but the optic nerve is also not affected, unlike retrobulbar anesthesia, where it is partially blocked. Since the state of the eye in topical anesthesia closely emulates the physiological state of the eye at rest, it affords better and faster visual recovery. Absence of post-operative chemosis, ecchymosis, or ptosis facilitate immediate visual recovery and therefore better patient satisfaction. $^{3}$

Our study was undertaken to study the effect of two different kinds of anesthesia being used for phacoemulsification surgery followed by IOL implantation, on central $\mathrm{ACD}$ and post-op refraction.

\section{Intraocular Pressure}

IOP has been shown to decrease after phacoemulsification due to a combination of mechanical factors (including lens removal) and dynamic factors (like increased uveoscleral and trabecular outflow). ${ }^{6,7}$ Dole et $\mathrm{al}^{7}$ documented an expansion of Schlemm's canal resulting in increased aqueous outflow, thus decreasing the IOP and increasing the ACD post-phacoemulsification. However, Cekic et $\mathrm{al}^{8}$ hypothesized that the increase in ACD after phacoemulsification could be attributed to thinner IOLs and the decrease in IOP was due to a decrease in aqueous outflow resistance. ${ }^{8}$

According to Sanford et al, ${ }^{9}$ the rise in IOP after peribulbar anesthesia was due to high volume of anesthetic agent in the peribulbar space, and this rise could be blunted by ocular compression, ${ }^{9}$ wherein ocular compression was proposed to decrease the vitreous volume. In contrast, after topical anesthesia, the intra-operative condition of the eye was similar to its pre-operative state, so the physiology of aqueous outflow was not altered as with ocular compression in the peribulbar group.

Table 5 Paired $t$-test for Comparison of ACD Change Between Two Groups (Inter-Group Comparison)

\begin{tabular}{|l|l|l|l|l|l|l|}
\hline Change & Group & N & Mean (mm) & SD & SE Mean & P-value \\
\hline Pre-Op - I Week & I & 55 & 0.583 & 0.20543 & 0.02745 & $<0.001$ \\
& II & 55 & 1.003 & 0.43957 & 0.05874 & 0.03227 \\
\hline Pre-Op - 6 Weeks & I & 55 & 0.7575 & 0.24152 & 0.43796 & 0.05852 \\
\hline
\end{tabular}




\section{Anterior Chamber Depth}

The increase in ACD after phacoemulsification was considered to be a result of a decrease in aqueous outflow resistance. The ocular compression (specifically after peribulbar anesthesia) deturged the vitreous cavity, thereby further increasing the ACD. This ocular compression, however, affected the final lens position on release of this pressure, ie, the ELP of IOL and, thus, the resultant post-operative visual outcome.

Our study also showed an increase in ACD postoperatively both at week 1 and week 6 in both groups of patients, thus supporting the various studies reporting an increase in ACD post-phacoemulsification.

Since the mechanism of action of both anesthetic techniques used in our study is different, so is their effect on anterior chamber configuration after surgery. In peribulbar anesthesia, there occurs an increase in total orbital volume owing to the $6-8 \mathrm{~mL}$ of anesthetic agent injected. This initially increases the intraocular and intra-orbital pressure, which pushes the globe and the intraocular contents forward. Digital ocular massage that is applied to combat this rise in pressure, moves the aqueous into the outflow channels, pushes the lens iris diaphragm posteriorly, and decreases the vitreous volume. Also, the peribulbar anesthesia relaxes the extraocular muscles as it diffuses in the extraconal space. This prevents the upthrust of intraocular contents due to any involuntary contraction by an anxious patient. All these dynamic factors along with mechanical factors result in a final deeper AC in this group of patients. Topical anesthetic agents, on the other hand, diffuse through the conjunctiva and cornea and anesthetize the AC. Since this technique requires no maneuvering preoperatively while preparing the patient, the pre-operative physiological status of the eye is maintained. This difference in mechanics is responsible for the difference in results with respect to ACD in both the groups.

\section{Post-Op Visual Outcome}

Refraction also varies with the ACD, as was put forward by Arai et $\mathrm{al}^{10}$ in their study. They proposed that changes in ACD may result in a change in visual acuity after cataract surgery and PCIOL implantation. Two schools of thought are prevalent in the literature about refractive outcomes after phacoemulsification with topical and peribulbar anesthesia. One opinion exists that refraction differs and is better with topical anesthesia, ${ }^{11,12}$ whereas the other refutes the above, claiming no change in post-op refractive outcome with the use of either of the two anesthetic techniques. ${ }^{7}$

ELP is an important determinant of post-operative refractive outcome of cataract surgery. Studies have shown that error in ELP estimation can account for $22-38 \%$ of predicted post-op refractive error. ${ }^{13}$ Error in predicting final axial position (ie, ELP) of IOL have great influence on post-op refractive results, either as myopic or hyperopic shift. ${ }^{14}$ Factors like IOL haptic design, ${ }^{15,16}$ IOL optic-haptic angulation, ${ }^{17}$ zonular strength, capsular fibrosis, etc, determine the ELP and thus the BCVA post-op.

\section{Effect of ACD on Post-Op Visual Outcome}

The stability of IOL depends upon zonular apparatus for maintaining the axial position, ie, ELP. Malpositioned IOL could cause sectoral shallowing of the AC. This change in position of IOL, ie, change in the ELP, would change the refractive outcome. In our study, dislocated or subluxated lens were excluded from the study. No patient developed zonular instability or zonular dialysis during the operation. All the study eyes had an in-the-bag IOL implantation with no complications like IOL-tilt or posterior capsular tear, thus maintaining the axial position of IOL.

Wirtitsch et al $^{15}$ conducted a prospective randomized study to compare the post-operative changes in ACD between single-piece vs multi-piece AcrySof IOLs and their effect on postoperative refractive shift. They concluded that single-piece IOLs shifted less than multi-piece IOLs postoperatively ${ }^{15}$ and therefore refraction stabilized faster with single-piece IOLs. In our study, the same hydrophilic acrylic foldable PCIOL was implanted in all patients; so IOL design and thickness could be eliminated as a probable confounding factor for statistically significantly different refractive results between the study groups.

Biometry of elective cataract surgery patients is done either under topical anesthesia or without anesthesia, ie, under physiological conditions. So in group I patients, the preoperative physiological condition of the eye is replicated and is identical to both the intra- and post-operative eye status.

Refractive outcome differs with change in AC dynamics and ACD. The ACD differed between the two groups significantly and so did our post-operative refraction. The ACD of eyes in the topical anesthesia group is lesser as compared to the peribulbar group, and so is their spherical equivalent; thus lesser increase in post-operative 
ACD may be responsible for predictably better unaided visual acuity.

\section{Conclusion}

Post-phacoemulsification, the ACD is more after peribulbar anesthesia, as compared to topical anesthesia. Post-op refractive outcome is better with the use of topical anesthesia.

\section{Ethical Standards}

All procedures performed in studies involving human participants were in accordance with the ethical standards of the institutional and/or national research committee and with the 1964 Helsinki declaration and its later amendments or comparable ethical standards.

\section{Informed Consent}

Informed consent was obtained from all individual participants included in the study.

\section{Funding}

There is no funding to report.

\section{Disclosure}

The authors report no conflicts of interest for this work.

\section{References}

1. Güngör SG, Akman A, Asena L, Aksoy M, Sezenöz AS. Changes in anterior chamber depth after phacoemulsification in pseudoexfoliative eyes and their effect on accuracy of intraocular lens power calculation. Turk J Ophthalmol. 2016;46(6):255-258. doi:10.4274/tjo.56659

2. Kershner RM. Topical anesthesia for small incision self sealing cataract surgery. A prospective evaluation of first 100 patients. $J$ Cataract Refract Surg. 1993;19(2):290-292. doi:10.1016/S0886-3350(13) 80958-3
3. Thevi T, Godinho MA. Trends and complications of local anaesthesia in cataract surgery: an 8-year analysis of 12992 patients. Br J Ophthalmol. 2016;100(12):1708-1713. doi:10.1136/bjophthalmol-2015-307785

4. Zehetmayer M, Radax U, Skorpik C, et al. Topical versus peribulbar anesthesia in clear corneal cataract surgery. $J$ Cataract Refract Surg. 1996;22(4):480-484. doi:10.1016/S0886-3350(96)80046-0

5. Waheeb S. Topical anesthesia in phacoemulsification. Oman J Ophthalmol. 2010;3(3):136-139. doi:10.4103/0974-620X.71892

6. Meyer MA, Savitt ML, Kopitas E. The effect of phacoemulsification on aqueous outflow facility. Ophthalmology. 1997;104:1221-1227.

7. Dole K, Kulkarni S, Shisode KD, et al. Comparison of clinical outcomes, patient, and surgeon satisfaction following topical versus peribulbar anesthesia for phacoemulsification and intraocular lens implantation: a randomized, control trial. Indian $J$ Ophthalmol. 2014;62(9):927-930. doi:10.4103/0301-4738.143929

8. Cekic O, Batman C, Totan Y, Zilelioglu O. Changes in anterior chamber depth and intraocular pressure after phacoemulsification and posterior chamber intraocular lens implantation. Ophthalmic Surg Lasers. 1998;29(8):639-642.

9. Sanford DK, Minoso O, Belyea DA. Response of intraocular pressure to retrobulbar and peribulbar anaesthesia. Ophthalmic Surg Lasers. 1998;29(10):815-817.

10. Arai M, Ohzuno I, Zako M. Anterior chamber depth after posterior chamber intraocular lens implantation. Acta Ophthalmol. 2009;72 (6):694-697. doi:10.1111/j.1755-3768.1994.tb04682.x

11. Rizvi Z, Rehman T, Malik S, et al. An evaluation of topical and local anesthesia in phacoemulsification. J Pak Med Assoc. 2003;53 (4):167-170.

12. Randleman JB, Srivastava SK, Aaron MM. Phacoemulsification with topical anesthesia performed by resident doctors. $J$ Cataract Refract Surg. 2004;30(1):149-154. doi:10.1016/S0886-3350(03)00491-7

13. Olsen T. Sources of error in intraocular lens calculation. $J$ Cataract Refract Surg. 1992;18(2):125-129. doi:10.1016/S0886-3350(13)80917-0

14. Erickson P. Effect of intraocular lens position error on postoperative refractive error. J Cataract Refract Surg. 1990;16(3):305-311. doi:10.1016/S0886-3350(13)80699-2

15. Writitsch MG, Findl O, Menapace R, et al. Effect of haptic design on change in axial lens position after cataract surgery. $J$ Cataract Refract Surg. 2004;30(1):45-51. doi:10.1016/S0886-3350(03)00459-0

16. Koeppl C, Findl O, Kriechbaum K, et al. Postoperative change in effective lens position of a 3 piece acrylic intraocular lens. $J$ Cataract Refract Surg. 2003;29(10):1974-1979. doi:10.1016/S0886-3350(02)02049-7

17. Patternel V, Menapace R, Findl O, et al. Effect of optic edge design and heptic angulation on postoperative intraocular lens position. $J$ Cataract Refract Surg. 2004;30(1):52-57. doi:10.1016/S08863350(03)00556-X
Clinical Ophthalmology

\section{Publish your work in this journal}

Clinical Ophthalmology is an international, peer-reviewed journal covering all subspecialties within ophthalmology. Key topics include: Optometry; Visual science; Pharmacology and drug therapy in eye diseases; Basic Sciences; Primary and Secondary eye care; Patient Safety and Quality of Care Improvements. This journal is indexed on PubMed

\section{Dovepress}

Central and CAS, and is the official journal of The Society of Clinical Ophthalmology (SCO). The manuscript management system is completely online and includes a very quick and fair peer-review system, which is all easy to use. Visit http://www.dovepress.com/ testimonials.php to read real quotes from published authors. 